\title{
The Degree of Tooth Colour Change After Using Different Concentrations of Carbamide Peroxide
}

\author{
Nataša Knežević ${ }^{1}$, Olivera Dolić2 ${ }^{\text {, Marija Obradović }}$, Željka Kojić ${ }^{3}$, Aleksandra \\ Đeri', Valentina Veselinović ${ }^{4}$, Slava Sukara²
}

\section{ABSTRACT}

Background: Depending on the cause of discoloration, bleaching materials and other factors, vital dental bleaching techniques may be professional (in-office dental bleaching), at-home night-guard bleaching and combined.

The main objective of this study was to determine, in vitro, tooth colour change using external dental bleaching techniques with $16 \%$ and $30 \%$ carbamide peroxide gel and to investigate the effect of concentration of carbamide peroxide gel on the bleaching success.

Method: This study included 20 extracted intact human teeth. Teeth were divided into two groups of ten each: the first group was bleached with $16 \%$ and the second group with $30 \%$ carbamide peroxide gel. The procedure was repeated three times for each tooth. The existing colour on each tooth was recorded using VITA classical shade guide A1-D4 before treatment, after each session and after bleaching was completed.

Results: A significant difference $(\mathrm{p}<0.01)$ was found between the first and the second bleaching treatment, for both concentrations (Exact binomial test). A significant difference $(\mathrm{p}<0.05)$ was also present between the second and the third treatment, while no statistically significant difference was found between the first and the third bleaching treatment, for both concentrations. There was no statistically significant difference between groups based on degree of tooth shade ( $\chi^{2}$ test).

Conclusion: The teeth bleaching technique with $16 \%$ carbamide peroxide gel and the teeth bleaching technique with 30\% carbamide peroxide gel have shown the same efficiency in changing the tooth colour.

Keywords: carbamide, peroxide, tooth, gels.
(1) Department of Restorative Dentistry, Faculty of Medicine, University of Banja Luka, the Republic of Srpska, Bosnia and Herzegovina.

(2) Department of Paediatric and Preventive Dentistry, Faculty of Medicine, University of Banja Luka, the Republic of Srpska, Bosnia and Herzegovina.

(3) Department of Periodontology and Oral Medicine, Faculty of Medicine, University of Banja Luka, the Republic of Srpska, Bosnia and Herzegovina.

(4) Department of Prosthodontics, Faculty of Medicine, University of Banja Luka, the Republic of Srpska, Bosnia and Herzegovina.

Correspondence:

NATAŠA KNEŽEVIĆ

E: natasa.knezevic@med.unibl.org M: +387 65544030

\section{ARTICLE INFO}

Received: 11 September 2019 Revision received: 8 October 2019 Accepted: 12 October 2019

\section{INTRODUCTION}

Dental bleaching is one of the fastest growing areas in restorative and aesthetic dentistry in the last few years. Earlier, it was thought that enamel colour was responsible for tooth colour. Later on, research has shown that four dental tissues: pulp, dentin, enamel and cement are involved in creating the final shade of each tooth. Any change in one of these structures leads to the tooth colour change, which is reflected on transmission change and light reflection. Dental discolorations have different aetiologies, locations, frequency and affinities to dental tissue. ${ }^{1-3}$

Depending on the cause of discoloration, bleaching materials and other factors, vital dental bleaching techniques may be professional (in-of- 
fice dental bleaching), at-home night-guard bleaching and combined. In recent years, overthe-counter dental bleaching products have become very popular. They are based on low concentrations of bleaching agents (3-6\% hydrogen peroxide gel) in the form of coloured rubber bands, splints, toothpastes. These self-applied bleaching treatments are administered without the consultation and supervision of a dentist. ${ }^{1,4-9}$

In-office dental bleaching techniques use high concentrations of hydrogen or carbamide peroxide gel. The gel is placed on a specific surface of the tooth and then activated chemically or by various light and heat sources. The main advantages of in-office bleaching technique are: procedure is completely under the control of the dentist, the soft tissue of the oral cavity is protected during the procedure and faster colour change. 1, 4-10

A very popular and effective dental bleaching technique of vital teeth is at-home night-guard bleaching, conducted by patient itself. The advantages of this technique are simple application and low concentration of bleaching agent (10-16\% carbamide peroxide gel). The process involves making a soft, vinyl individual spoon or tray for bleaching gel application. Bleaching treatment with this technique lasts from two to six weeks, depending on the intensity of tooth discoloration. Regular dental check-ups are needed to determine colour change as well as possible soft tissue damage and sensitivity. Increased salivation occurs frequently in patients while wearing a splint, which is a common occurrence due to $\mathrm{pH}$ change in the mouth. ${ }^{1,3,5,8-17}$

Zekonis et al. examined colour change, recurrence of discoloration and tooth sensitivity after performing two different dental bleaching techniques in the same patient. In-office bleaching technique with $35 \%$ hydrogen peroxide gel was used on one half of the upper jaw of the subjects, while at-home night-guard bleaching technique with $10 \%$ carbamide peroxide gel was applied on the other half. The results of the study showed that $84 \%$ of respondents consider that home night-guard bleaching techniques are more effective in colour change. There was no statistical difference between dental bleaching techniques related to tooth sensitivity in patients. ${ }^{18}$

The bleaching effect depends on various factors such as dental plaque, temperature, $\mathrm{pH}$, tooth isolation and most importantly, on bleaching gel concentration and the application time. The application time is directly proportional to the positive tooth colour change. ${ }^{1}$

The main objective of this study was to determine, in vitro, tooth colour change by using external dental bleaching techniques with $16 \%$ and $30 \%$ carbamide peroxide gel and to investigate the effect of concentration of carbamide peroxide gel on the bleaching success.

\section{METHOD}

The study is a part of dissertation conducted on Faculty of Medicine, University of Banja Luka and included 20 extracted intact human teeth. All teeth were extracted at the Public Health Institute of Dentistry Banja Luka for orthodontic or periodontal reasons. Teeth were cleaned of soft deposits and calculus and kept in saline until the experiment. They were divided into two groups of ten teeth each: the first group was bleached with $16 \%$ carbamide peroxide gel (Vivastyle $16 \%$, Ivoclar Vivadent, Liechtenstein) and the second group with 30\% carbamide peroxide gel (Vivastyle 30\%, Ivoclar Vivadent, Liechtenstein).

Before treatment, the existing colour of every tooth was recorded by using VITA classical shade guide A1-D4 (VITA Zahnfabrik, Bad Säckingen, Germany). External bleaching technique was done for all teeth.

In the first group, $16 \%$ carbamide peroxide gel (Vivastyle 16\%, Ivoclar Vivadent, Liechtenstein) was applied to the vestibular surface of each tooth for 30 minutes, then the tooth was washed with water and dried, and the procedure repeated three times. This method of dental bleaching is equivalent with at-home night-guard vital teeth bleaching technique, modified for the purposes of this study.

In the second group, 30\% carbamide peroxide gel (Vivastyle 30\%, Ivoclar Vivadent, Liechtenstein) was applied to the vestibular surface of each tooth for 15 minutes, after that, washed with water and dried. This procedure was repeated twice. Performed method of tooth bleaching is equivalent with in-office professional teeth bleaching technique, modified for the purposes of this study. 
The bleaching process was repeated in same manner after seven and fourteen days. In between, teeth were stored in fresh sterile saline. Overall, bleaching process was performed three times. If the tested tooth did not change its shade after two bleaching processes it was excluded from the third procedure. ${ }^{1}$

After each procedure, the tooth colour change was evaluated based on the 'dark-light scale' (Table 1). On this scale, each tooth shade was assigned a corresponding number from one to 16 , so that statistics could be done. The lightest colour on the scale (B1) corresponds to number one, while the darkest colour $\left(\mathrm{C}_{4}\right)$ corresponds to number 16 . One degree of shade change is represented by moving from a higher to a lower number on the scale (eg from shade $\mathrm{C}_{2}$ to $\mathrm{C} 1$, means from number 7 to 6 ), two degrees for two numbers (eg from B4 to B3 is actually from 13 to 11) and consequently, three degrees for three numbers (eg from A2 to colour A1 or from 5 to 2). ${ }^{1,19}$

Statistical data processing was done using $\chi^{2}$ and exact binomial test.

Table 1: Dark-light scale of tooth shade

\begin{tabular}{lllllllllllllllll}
\hline Vita shade guide & B1 & A1 & B2 & D2 & A2 & C1 & C2 & D4 & A3 & D3 & B3 & A3,5 & B4 & C3 & A4 & C4 \\
\hline Shade number & 1 & 2 & 3 & 4 & 5 & 6 & 7 & 8 & 9 & 10 & 11 & 12 & 13 & 14 & 15 & 16
\end{tabular}

\section{RESULTS}

Bleaching with $16 \%$ carbamide peroxide was unsuccessful in all ten teeth (100\%) as seen in Table 2. After the second treatment, six teeth (60\%) changed their shade to the lighter, while in third treatment no change of shade was observed in any of the six tested teeth (four teeth were excluded from the third process due to the unchanged shade after the first two procedures). High statistically significant difference was found ( $p<0.01)$ between the first and the second bleaching treatment (exact binomial test). A statistically significant difference $(\mathrm{p}<0.05)$ was also present between the second and third treatments. No statistically significant difference was found between the first and the third bleaching treatments.
In a group of teeth bleached with 30\% carbamide peroxide, only one tooth (10\%) after the first treatment changed its shade into the lighter. After the second treatment eight teeth $(80 \%)$ underwent a shade change and after the third process, only two of them underwent a shade change (20\%) (Table 2). In this group results of exact binomial test showed that there was a highly statistically significant difference $(p<0.01)$ between the first and the second treatment, while the difference between the first and the third treatment was not significant. A statistically significant difference was also found between the second and the third treatment $(\mathrm{p}<0.05)$.

In a group of teeth bleached with $16 \%$ carba-

Table 2: Success rate of teeth bleaching with two different carbamide peroxide concentracion depending on the number of treatments.

\begin{tabular}{|c|c|c|c|c|c|c|c|}
\hline \multicolumn{2}{|r|}{ Carbamide peroxide concentration } & \multicolumn{2}{|c|}{$\begin{array}{l}\text { After first } \\
\text { treatment }\end{array}$} & \multicolumn{2}{|c|}{$\begin{array}{l}\text { After second } \\
\text { treatment }\end{array}$} & \multicolumn{2}{|c|}{$\begin{array}{l}\text { After third } \\
\text { treatment }\end{array}$} \\
\hline & & $\mathbf{n}$ & $\%$ & n & $\%$ & $\mathbf{N}$ & $\%$ \\
\hline \multirow{2}{*}{$16 \%$} & teeth that have changed their color & 0 & 0 & 6 & 60 & 0 & 0 \\
\hline & teeth that have not changed their color & 10 & 100 & 4 & 40 & 6 & 100 \\
\hline \multirow{2}{*}{$30 \%$} & teeth that have changed their color & 1 & 10 & 8 & 80 & 2 & 20 \\
\hline & teeth that have not changed their color & 9 & 90 & 2 & 20 & 6 & 80 \\
\hline
\end{tabular}


Table 3: Degrees of success of teeth bleaching with two different concentrations of carbamide peroxide

\begin{tabular}{|c|c|c|c|c|c|c|c|c|c|}
\hline \multirow{2}{*}{$\begin{array}{l}\text { Carbamide peroxide } \\
\text { concentration }\end{array}$} & \multicolumn{2}{|c|}{$\begin{array}{l}\text { One } \\
\text { degree }\end{array}$} & \multicolumn{2}{|c|}{$\begin{array}{l}\text { Two } \\
\text { degree }\end{array}$} & \multicolumn{2}{|c|}{$\begin{array}{l}\text { Three } \\
\text { degree }\end{array}$} & \multicolumn{2}{|c|}{ Total } & \multirow[t]{2}{*}{$\mathrm{X}^{2}$ test } \\
\hline & $\mathrm{n}$ & $\%$ & $\mathbf{n}$ & $\%$ & $n$ & $\%$ & n & $\%$ & \\
\hline $16 \%$ & 5 & 83.33 & 1 & 16.67 & 0 & 0 & 6 & 100 & \multirow{2}{*}{$p>0.05$} \\
\hline $30 \%$ & 6 & 75.00 & 2 & 25.00 & 0 & 0 & 8 & 100 & \\
\hline
\end{tabular}

$\mathrm{p}=$ statistic value, $\mathrm{X}^{2}$ test $=$ test- $\mathrm{Hi}$ quadrate test

mide peroxide, five teeth $(83.33 \%)$ underwent one-degree of shade change, while only one tooth (16.67\%) underwent two degrees. No tooth changed its shade for three degrees (Table 3).

In a group of $30 \%$ carbamide peroxide six teeth (75.00\%) changed their shade for one degree,

\section{DISCUSSION}

Tooth discoloration is a major aesthetic problem. In modern dentistry, there is a tendency for patients and dentists to restore discoloured teeth to the natural colour of their teeth, to achieve the best possible aesthetics and to avoid prosthetic dental rehabilitation.

Observing the colour change through the number of bleaching treatments for both gel concentrations (16\% and 30\%), bleaching was most effective after the second treatment. Colour change did not occur in any of teeth after the second treatment. It can possibly be explained with so called 'Saturation point'. Carbamide peroxide dissolves in situ to urea, ammonia, carbon dioxide, water and hydrogen peroxide, which is the active substance. Hydrogen peroxide diffuses throughout the organic matrix and releases free radicals. Further on, these free radicals break down the double unsaturated bonds of the pigment molecules that produce smaller molecules that reflect less light. This is a bleaching process. If the process continues at some point the 'saturation point' is reached. The 'saturation point' is the point when the maximum bleaching is achieved. From this stage, the pigments are no longer bleached, and the bleaching agent begins to act on other carbon compounds, such as enamel matrix proteins and at this point, a loss of tooth structure can start. Therefore, a clinician needs to know when to stop the bleaching process. If it continues, complete disintegration of hard dental tissues can appear. ${ }^{1,20}$ two teeth (25.00\%) for two degrees, while no tooth had a three-degree change (Table 3 ).

$\chi 2$ test showed no statistical difference between groups based on degree of tooth shade change (Table 3).
The results of this study showed the same efficiency in the degree of tooth colour change in group of teeth bleached with a higher carbamide peroxide concentration (30\%) - shorter exposition time (two applications for a duration of 15 min) and in the group of teeth bleached with a lower (16\%) carbamide peroxide concentration - longer exposition time (three applications for a duration of $30 \mathrm{~min}$ ). This study confirmed that the application time of bleaching agent played a major role in the success of vital teeth bleaching. The application time is directly proportional to the positive tooth colour change. Low concentrations of bleaching agents can achieve satisfactory and equally good teeth bleaching results as agents with high concentrations, if the agent is applied to the tooth for an extended period of time. ${ }^{1,18,21-23}$

Meireles et al also showed that the time of exposure to a bleaching agent is a more important factor than gel concentration itself. A satisfactory tooth colour was achieved with multiple treatments despite the carbamide peroxide concentration. Therefore, the authors propose the use of low carbamide peroxide concentrations for vital teeth bleaching, and that is in line with American Dental Association (ADA) proposal. ${ }^{21}$

Other authors examined the colour change on intact bovine incisors. Tooth colour was determined by a spectrophotometer (Easyshade, Vita Zahnfabrik, Germany). Teeth were bleached 
with $10 \%$ and $16 \%$ carbamide peroxide (four hours a day, for two weeks) and 37\% carbamide peroxide (three times for 20 minutes in one session, for three sessions). This study showed that after the first week of bleaching, $10 \%$ and $16 \%$ of carbamide peroxide were significantly more effective than $37 \%$ of carbamide peroxide. At the end of the bleaching treatment, there was no statistically significant difference in the bleaching success among the $10 \%, 16 \%$, and $37 \%$ carbamide peroxide. The same efficiency of athome and in-office-bleaching techniques was observed. The authors recommend the use of low concentrations of bleaching agents and the use of at-home bleaching technique. ${ }^{21}$

Moghadam at al examined the success of colour change, long term effect and teeth sensitivity associated with in-office and at-home bleaching techniques. Half of the subjects were involved in at-night bleaching of maxillary teeth (Opalescence $15 \%$, Ultradent, South Jordan, UT, USA) and in-office bleaching of mandibular teeth (WHITE XTRA 38\%, Bydental, Maltinti, Italy), while the other half of subjects were assigned for office bleaching of maxillary teeth and athome bleaching of mandibular teeth, with same agents. Participants were followed for two weeks and one, three and six months after the bleaching process. Tooth colour in all patients was determined by using a colour key and a spectrophotometer. This study showed that there was no difference in the degree of colour change between two bleaching techniques or in terms of colour regression immediately after bleaching and at two weeks, one month and three months from the end of treatment. The both bleaching methods are clinically identical at different time intervals in post-treatment sensitivity. ${ }^{22}$

Mounika et al examined the effectiveness of different concentrations of carbamide and hydrogen peroxide on the degree of colour change of vital teeth. Teeth were bleached by in-office bleaching technique with $35 \%$ hydrogen peroxide, three times for 15 minutes per session, in three sessions and at-home bleaching technique with $16 \%$ carbamide peroxide, three weeks, eight hours a day. The colour assessment was performed with a spectrophotometer before the bleaching process and after one, two, three and four weeks, or three and six months after the bleaching process was completed. The results of this study showed the same efficacy in tooth colour changes with both bleaching techniques, which confirms the findings of other studies that tooth exposure time to the bleaching agent is more important in the bleaching process than the agent concentration. The dye regression occurred between three and six months after the bleaching process in both techniques. ${ }^{23}$

Using at-night and in-office vital teeth bleaching techniques, Matis et al tested the effects of different concentrations of hydrogen peroxide (15\%, 25\%, 30\%, 35\%, 40\%) on colour changes and its persistence after the bleaching process was completed. Tooth colour was determined before bleaching, immediately after bleaching process and one, two, four and six weeks after the bleaching treatment using a colorimeter and colour key. All types of agents have shown efficacy in colour changes. Three of the four bleaching agents with the lowest concentration had the largest colour changes immediately after bleaching, while the three bleaching agents with the shortest contact time showed the smallest colour changes. From the results of this study it can be concluded that the contact time of the bleaching agent with the tooth was more important than the concentration of the agent.. ${ }^{24}$

In conclusion, the teeth bleaching technique with $16 \%$ carbamide peroxide gel and the teeth bleaching technique with 30\% carbamide peroxide gel have shown the same efficiency in tooth colour changes.

\section{ACKNOWLEDGEMENTS}

None.

\section{CONFLICT OF INTEREST}

None.

\section{REFERENCES}

1. Savić-Stanković T. [Effects of preparations with various concentrations for teeth bleaching]. Belgrade: University of Belegrade - Faculty of Dental Medicine, 2008. [MSc thesis]. Serbian.

2. Sulieman M, Addy M, Rees JS. Development and evaluation of a method in vitro to study the effectiveness of tooth bleaching. J Dentistry 2003;31(6):415-22. 
3. Zimmerli B, Jeger F, Lussi A. Bleaching of nonvital teeth. Schweiz Monatsschr Zahnmed 2010;120:30613 .

4. Goldberg M, Bohin F, Bonnet E, Claisse-Crinquette A, Dartigues J, Louis JJ, et al. Association Dentaire Française (ADF) Medical Devices Commission: Tooth bleaching treatments - A review [Internet]. Paris: ADF; c2007 [cited 2019 Oct 09]. Available from: http://www.adf.asso.fr/pdf/DossiersADF_EN/ TOOTH-BLEACHING.pdf.

5. Strassler HE. The Baltimore College of Dental Surgery, University of Maryland Dental School. Continuing Education: Vital tooth bleaching: an update. 2006. [Internet]. Baltimore: University of Maryland Dental School [cited 2019 Oct o9]. Available from: http://citeseerx.ist.psu.edu/viewdoc/download?doi=10.1.1.520.7025\&rep $=$ rep1\&type $=$ pdf.

6. Paliska J, Stipetić A, Tarle Z, Ristić M, Ban T, Vujičić N, Pichler G. [Colorimetric evaluation of the effectiveness of various teeth bleaching procedures]. Acta Stomatol Croat 2011;45(4); 258-67. Croatian.

7. Koleoso U. Tooth bleaching: current concepts of the procedure in cosmetic dentistry. Nig Qt J Hosp Med 2004;14(3-4):236-9.

8. Oteo Calatayud J, Mateos P, Oteo CC, Calvo BMJ. Comparative clinical study of two tooth bleaching protocols with 6\% hydrogen peroxide. Int J Dentistry 2009:1-5. doi: 10.1155/2009/928306

9. Alqahtani MQ. Tooth-bleaching procedures and their controversial effects: a literature review. Saudi Dent J 2014;26(2):33-46.

10. Restrepo-Kennedy N. Effect of dehydration on in-office bleaching colour changes. Des Moines, IO: University of Iowa. 2012. [MSc thesis].

11. Lima FG, Rotta TA, Penso S, Meireles SS, Demarco FF. In vitro evaluation of the whitening effect of mouth rinses containing hydrogen peroxide. Braz Oral Res 2012;26(3):269-74.

12. Rotstein I. Tooth discoloration and bleaching. Endodontics 2011;16:845-60.

13. Hermeler L. Professional in-office whitening of non-vi- tal teeth. J Cosmet Dent 2011;27(1):34-5.

14. Haywood VB. History, safety, and effectiveness of current bleaching techniques and applications of the night guard vital bleaching technique. Quintessence Int 1992;23:488; 471.

15. Fearon J. Tooth whitening: concepts and controversies. Int Dent 2007;11(2):24-38.

16. Ari H, Ungor M. In vitro comparison of different types of sodium perborate used for intracoronal bleaching of discoloured teeth. Int Endod J 2002;35(5):433-6.

17. Castellucci A, Lemon R. Bleaching non vital and vital teeth. Endodontics 2011;31(1):904-5.

18. Zekonis R, Matis BA, Cochran MA, Al Shetri SE, Eckert GJ, Carlson TJ. Clinical evaluation of in-office and at-home bleaching treatments. Oper Dent 2003; 28(2):114-21.

19. Bernardon JK, Sartori N, Ballarin A, Perdigão J, Lopes G, Baratieri LN. Clinical performance of vital bleaching techniques. Oper Dent 2010;35(1):3-10.

20. Calazans F, Dias K, Miranda M. Modified Technique for Vital Bleaching of Teeth Pigmented by Amalgam: A Case Report. Oper Dent 2011;36(6):678-82.

21. Meireles SS, Fontes ST, Coimbra LAA, Bona ÁD, Demarco FF. Effectiveness of different carbamide peroxide concentrations used for tooth bleaching: an in vitro study. J Appl Oral Sci 2012;20(2):186-91.

22. Moghadam FV, Majidinia S, Chasteen J, Ghavamnasiri M. The degree of color change, rebound effect and sensitivity of bleached teeth associated with at-home and power bleaching techniques: a randomized clinical trial. Eur J Dent 2013;7(4):405-11.

23. Mounika A, Mandava J, Roopesh B, Karri G. Clinical evaluation of color change and tooth sensitivity with in-office and home bleaching treatments. Indian $\mathrm{J}$ Dent Res 2018;29(4):423-7.

24. Matis BA, Cochran MA, Franco M, Al-Ammar W, Eckert GJ, Stropes M. Eight in-office tooth whitening systems evaluated in vivo: a pilot study. Oper Dent 2007;32(4):322-7. 